\title{
The antimicrobial effect of piper betel leaves extract against Streptococcus mutans
}

\author{
Liyana Mohammad Subri*, Warta Dewi*, Mieke Hemiawati Satari* \\ *Department of Oral Biology Faculty of Dentistry Universitas Padjadjaran
}

\begin{abstract}
Introduction: Betel leaves are herbal plant that is believed to have phenolic compound as an antimicrobial agent. One of the medical plants (herbal) which has an-timicrobial properties is Piper betel.The aim of this research is to analyzed the antimicrobial effect of Piper Betel Leaves extract against Streptococcus mutans. Methods: Type of this research is laboratory experiment. Population of this study are Piper betle Linn plant in West Java. The MIC test were conducted based on serial dilution method in $64 \%, 32 \%, 16 \%, 8 \%, 4 \%, 2 \%, 1 \%, 0.5 \%, 0.25 \%, 0.125 \%$ concentration of Piper betel leaves extracts against 5 sample of Streptococcus mutans within three repetitions. Results: The result shows that $0.25 \%$ concentration of Piper betel leaves extract can inhibit Streptococcus mutans. Conclusion: Piper betel leaves extract can inhibit the growth and had antimicrobial effect against Streptococcus mutans.
\end{abstract}

Key words: Antimicrobial effect, piper betel leaves extract, Streptococcus mutans.

\section{INTRODUCTION}

Dental caries (tooth decay), one of the most com-mon infectious disease in humans, is still a signif-icant public health problem in several countries. ${ }^{1}$ Based on the epidemiology study in United States shows that around $4-5 \%$ of the population around the world suffering periodontal disease after caries. Changes in caries pattern in developed countries are expected to have a dramatic effect on the nature of operative dentistry practice in the near future. ${ }^{2}$ The incidence of caries in large populations has closely paralleled the industrialization of nations. As wealth has increased, so has sugar consumption in the form of foods and confections. In modern times, fluoridation of water systems, as well as the presence of fluoride in packaged foods and beverages, has greatly reduced the incidence of dental caries in the population of the industrial countries. Nevertheless, reducing the risk of caries depends on behavior and access to dental care. $^{3}$

Caries is one of the most common diseases and has been defined as "a disease of the calcified bone tissues of the teeth resulting from the action of micro-organisms on carbohydrates, characterized by decalcification of the inorganic portions of the tooth and accompanied or followed by disintegration of the organic portion". Caries is a bacterial decay of the tooth structure brought about by the release of acids from oral bacteria (Streptococcus mutan, Streptococcus sobrinus) fermentin the tooth surface. ${ }^{4}$ Streptococcus mutans is one of

Corresponding author: Warta Dewi, Department of Oral Biology, Faculty of Dentistry Universitas Padjadjaran, Indonesia. Jalan Sekeloa Selatan I, Bandung, West Java, Indonesia, 40132; Phone: +6222-2504985/2532805 
the bacteria that have the main role that cause dental caries in humans. This bacteria is usually in combination with Streptococcus sobrinus on decaying teeth. Biofilm of the two organism form from a mix sugar, built up of plaque, and growth of colonies due to ideal growing conditions in a $\mathrm{pH}$ between $\mathrm{pH} 3.0$ to $\mathrm{pH7}$.5. Lactic acid from fermenting sugars by the bacterias and built up plaque eat through the enamel protection layer of the teeth, which re-sults in cavity formation. ${ }^{5}$ Epidemiological studies have reported that Streptococcus mutans is more prevalent than Streptococcus sobrinus in dental plaque. ${ }^{6,2}$

There are several ideas to overcome the caries problem in the world such as control the content in daily diet, mechanical actions and by using the antibacterial products such as antiseptic. As the antiseptic materials is used in mouthrinse. ${ }^{5}$ In view of this, the search for new antimicrobial agents continues unabated. Medical plants are promising resources. The use of medical plants as screening pool for novel an-timicrobial agent has several advantages related to safety, availability, and minimizing the risk of side effects and addiction. ${ }^{7}$ The World Health Organization adopted a major policy change in accepting that most developing nations would have to make use of more traditional med-ical practices for primary health care. ${ }^{8}$ One of the medical plants (herbal) which has an-timicrobial properties is Piper betel. Piper betel is a glabrous climbing vine belonging to the family Piperaceae. It is abundantly distributed in many Asian countries. The leaves have been used in traditional medicine as carminative, stimulant, antifungal, and antimicrobial agent. The volatile oil known as Betel oil is the chief constituent of the leaves. Piper betel can be of great benefit in treating diseases caused by bacteria and fungi. Previous studies on this plant, roots and whole extract (mixture of volatile and non-volatile) of the green variety showed a very strong antimicrobial activity. ${ }^{9}$

In addition, the Piper betel leaves contain pheno-lic compound which is recognized by the American Dental Association as a material that has an anti-microbial activity which is can destruct the mem-brane cell. ${ }^{10}$ This compound also can reduce plaque accumulation which is the main cause of caries. ${ }^{11}$ Based on the problems above, the study was con-ducted to prove that the Piper betel extract that contain phenolic compond is the chief constitu-ent that causes its antimicrobial activity towards the Streptococcus mutans and also can reduce the production of caries. This study is to know the effect of the Betel leaf extract concentrations against the Streptococcus mutans in inhibiting the bacterial growth by using in vitro technique.he aim of this experimental study was to assess the antimicrobial effect of Piper Betel Leaves extract against Streptococcus mutans as cariogenic bacteria.

\section{METHODS}

Type of this research is laboratory experiment. research is to find out Piper betel leaves extract contained phenolic compound has antimicrobial effect towards Streptococcus mutans by searching for minimum inhibitory concentration (MIC) of the Piper betel leaves extract. Population of this study are Piper betle Linn plant in west Java. Sample: 100 grams of Piper betel leaves from Piper betel Linn plant in Cimahi, west Java.

The MIC test were conducted based on serial dilution method in $64 \%, 32 \%, 16 \%, 8 \%, 4 \%, 2 \%, 1 \%$, $0.5 \%, 0.25 \%, 0.125 \%$ concentration of Piper betel leaves extracts against 5 sample of Streptococcus mutans within three repetitions.

\section{RESULTS}

The bacteria is taken from the bacteria collection and then incubated culture on the TYCSB agar for 24 hours at $37^{\circ} \mathrm{C}$ in facultative anaerobically. It showed the growth of bacteria colonies. The col-onies appeared tiny white colonies within a clear outer zone. The colonies are strongly attached on the surface of TYCSB agar and also have irregu- lar or unsmooth bulgy colonies or simply it said to have a crystal cauliflower appearance. Then, the colonies were examined microscopical-ly with 10x100 magnification using Gram staining. The test was done as supporting test to prove it is a streptococcus species. This examination showed Gram-positive cocci in chains. Besides, it can maintain the purple color of crystal violet although has been washed with $95 \%$ alcohol and given of fuchsin dye, hence the colonies can be suspected as Streptococcus species. 


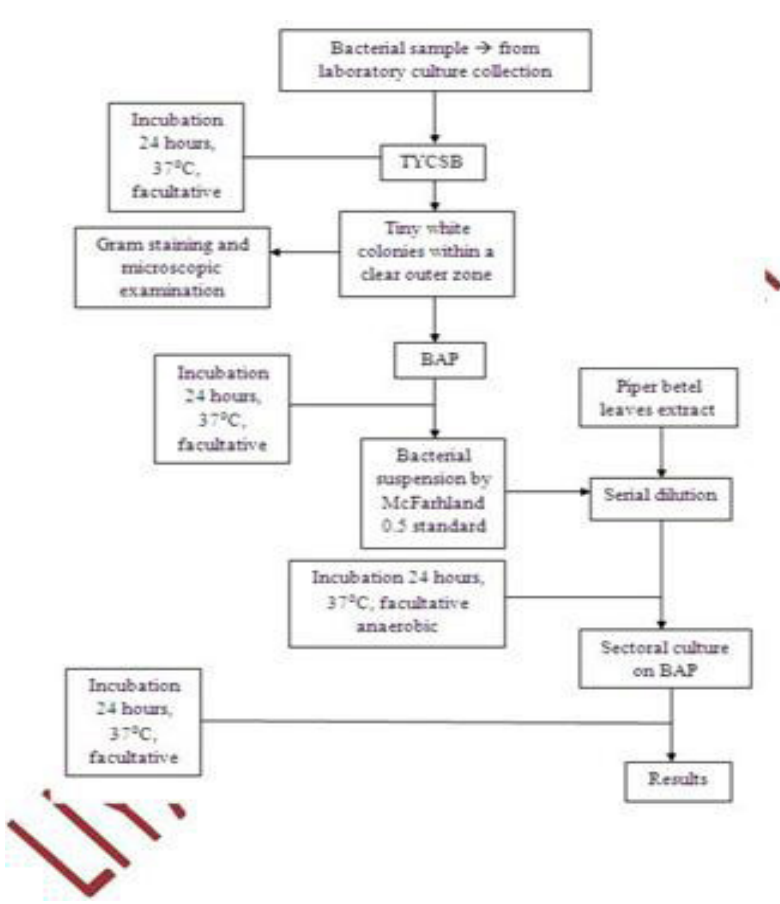

Figure 1 Steps Sequence Chart

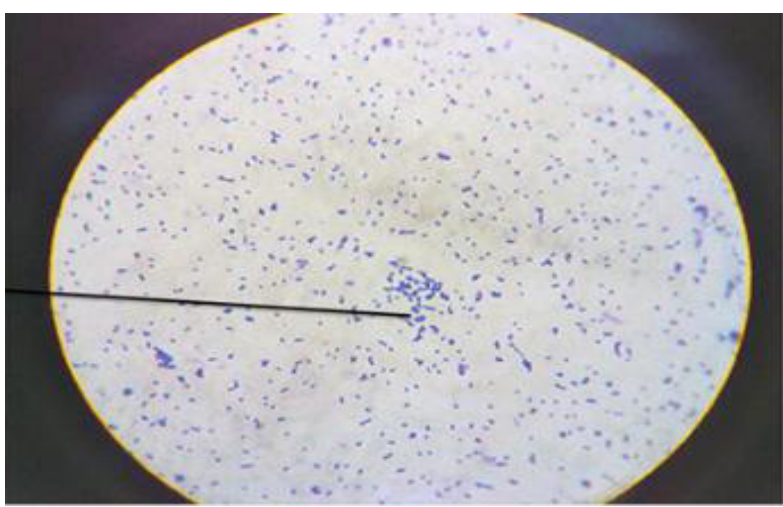

Figure 2 Colonies of Streptococcus mutans on TYCSB Agar Streptoccocus mutans (picture taken by author).

Result from incubated Streptococcus mutans in serial dilution test tubes didn't really showed cloudy differences because of the dark colour of the Piper betel leaves extract. Result by the culture in blood agar showed no bacterial growth of Streptococcus mutans in test tube 1 to 8. The colony began in test tube 9 and The test tube 11 is the negative control (Piper betel leaves extract with $0.125 \%$ concentration) while test tube 12 which is the positive control containing Streptococcus mutans with PEG stan-dardized with cell suspension $(0.1 \mathrm{~mL})$ following McFahrland 0.5 standard which contain $1.5 \times 108 \mathrm{CVU} / \mathrm{mL}$.

Three times repetition of the test for each 5 sample of Streptococcus mutans gave the same results

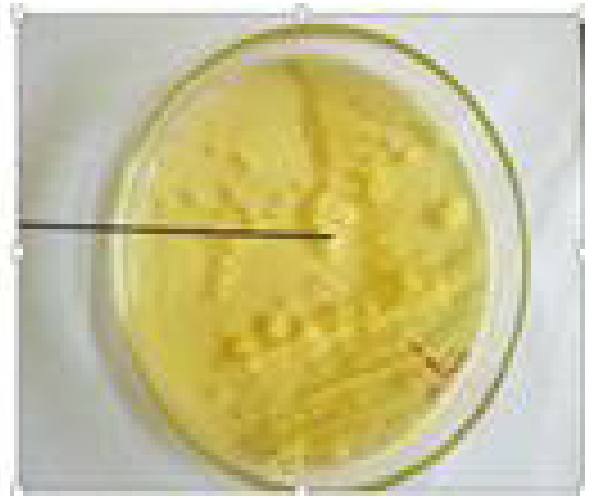

Figure $3 \mathrm{Gram}$-staining of (picture taken by author)

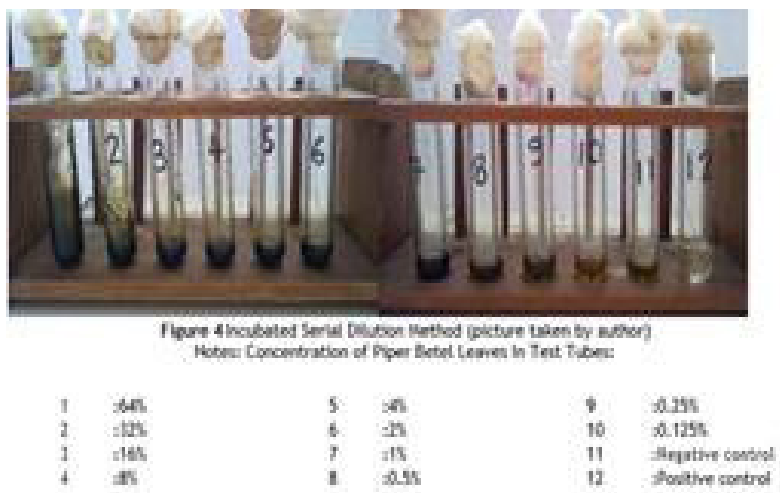

Figure 4 Incubated Serial Dilution Method (picture taken by author)

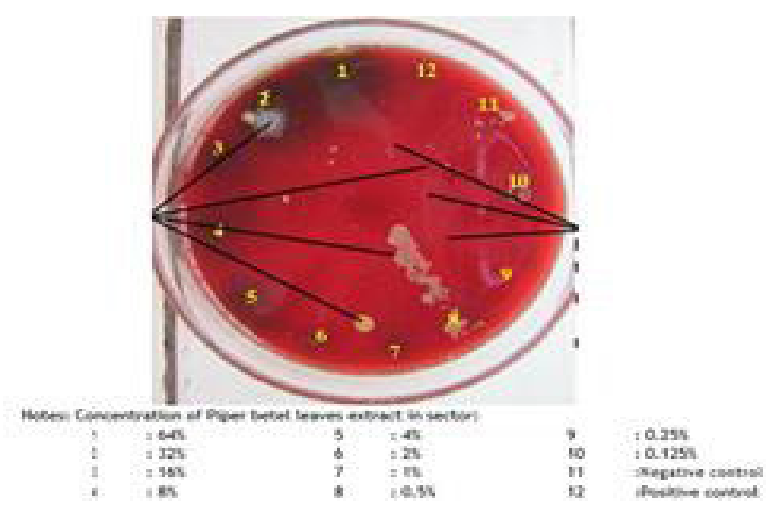

Figure 4 Determination of MIC based on Sectoral Culture of Streptococcusmutanson BAP

which there are growing of Streptococcus mutans but different quantity of the colonies. In the sector 12 which is the positive control that containing Table 1Sectoral Culture of Streptococcus mutans on Blood Agar Plate in Different Concentrations of Piper Betel Leaves Extract

Streptococcus mutans with PEG standardized with cell suspension $(0.1 \mathrm{~mL})$ following McFahrland 0.5 
Table 1. Sectoral Culture of Streptococcus mutans on Blood Agar Plate in Different Concentrations of Piper Betel Leaves Extract

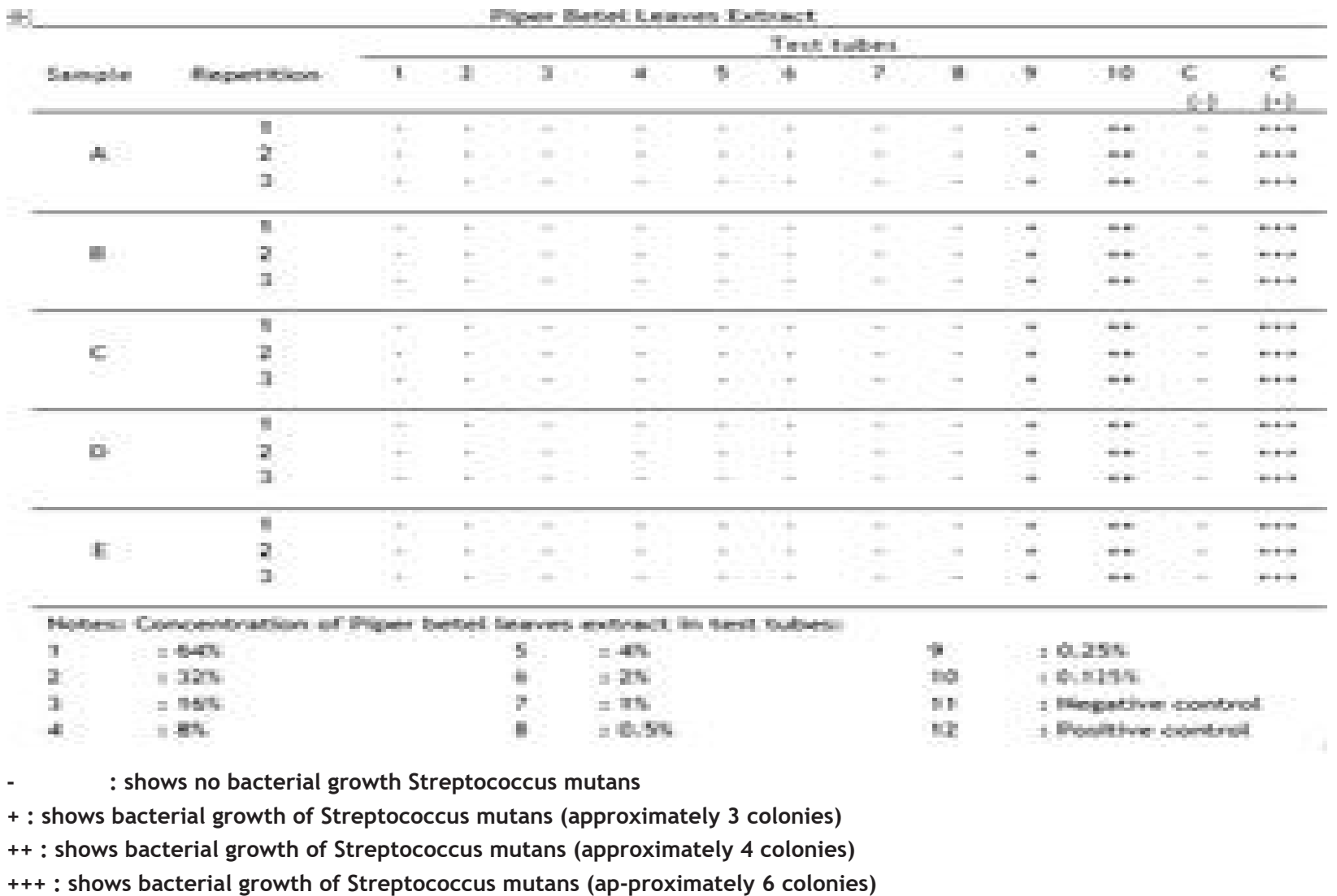

standard which contain $1.5 \times 108 \mathrm{CVU} / \mathrm{mL}$ appear about 6 colonies. The sector 9 has half of the sector 12 colonies, while the sector 10 has more than sector 9 colonies, about 4 colonies. It means that the MIC of Piper betel leaves extract against Streptococcus mutans is the concentration of the test tube 9 which is $0.25 \%$ Piper betel leaves extract concentrations.

\section{DISCUSSION}

TYCSB is used to identify the Streptococcus mutans. The colonies appeared tiny white colonies within a clear outer zone. They are strongly attached on the surface of TYCSB agar and also have irregular or unsmooth bulgy colonies or simply it said to have a crystal cauliflower appearance.

The content of glucan in the TYCSB cause the bacteria to attached strongly on the agar's surface. There is a study saying that TYCSB is the most sen-sitive and selective media to culture Streptococ-cus mutans for laboratory and clinical. ${ }^{12}$ The TYCSB is the only media that allows the visual differentiation of Streptococcus mutans and Streptococcus sobrinus. ${ }^{13}$

TYCSB agar was originally modified from tryp-tone-yeast extract -cycteine (TYC) agar. ${ }^{14}$ The addition of optimal levels of sucrose and bacitracin enhanced TYCSB agar's se-lectivity while its sensitivity is maintained. While some agreed that TYCSB permitted greater re-covery of Streptococcus mutans than other media. ${ }^{14}$

\section{CONCLUSION}

Piper betel leaves extract has the antimicrobial effect against Streptococcus mutans.

\section{REFERENCES}

1. F.J. Ramos-Gomes, J.A. Weintraub, A.S. Gansky, C.I. Hoover, J.D. Featherstone. 2002. Bac-terial, behavioral, and environment factors asso-ciated with early childhood caries. J. Clin. Pedi-atr. Dent. 26:165-173.

2. J.D. Bader, D.A. Shugars, A.J. Bonito. 2001: A systemic review of selected caries prevention and management methods, Community 
Dent Oral Epidemiol 29:399-411.

3. R.J. Lamont, M.S. Lantz, R.A. Burne, D.J. Leblanc. 2006. Oral microbiology and immunolo-gy, american society for microbiology, Washington DC, 53-55, 119, 253.

4. A. Fraser, Hale. 2004. Dental caries. Hale, DVM, FAVD, Dipl AVD. Hale Veterinary Clinic. 1-4.

5. Samaranayake, L.P. 2005. Essential Microbiology for dentistry 2 nd Ed. London. Churchill Livingstone

6. W.I. Loesche. 1986. Role of Treptococcus mutans in human dental decay. Microbiol. Rev. 50: $353-380$.

7. S. Lee, Dong-Sun Shin, Ju Sun Kim, KiBong Oh, Sam Kik Kang. 2003. Antibacterial Coumarins from Angelica gigas Roots. Archives of pharmacal Research, vol. 26(6): 449

8. R. Yuan, and A.Y. Lin. 2005. Traditional Chines Medicine. Available online at http:// qi-journal.com/tcm.asp.http: / / www. aworldofaro-matherapy.com/Essentialoils (Accessed on August 2011).

9. Jenie, B. S. L. 2001. Antimicrobial Activi-ty of Piper betle Linn Extract towards Foodborne
Pathogens and food spoilage microorganisms, FT annual meeting, new Orleans, Louisiana.

10. G.F. Brooks, J.S. Butel, A.M. Stephen. 2004. Jawetz, Melaick, \& Adelberg's Medical Microbiology. 23rd ed. Mc Graw Hill Companies Inc. Singapore

11. I.D. Mandel. 1993. Caries prevention- a continuing need, Int Dent J 43:67-70. Inhibitor of cell wall synthesis. 2011. Available online at http://denikrisna.files.wordpress. com $/ 2010 / 11 / \quad$ cell-wall.jpg?w=300\&h $=191$ (accessed on Decem-ber 2011)

12. A.K.L. Wan, W.K. Seow, L.J. Walsh, and P.S. Bird. 2002. Comparison of five selective media for the growth and enumeration of Streptococcus mutans. Australian Dental Jurnal 47:(1):21-26.

13. M. Svanberg, B. Krasse. 1990. Compara-tive recovery of mutans streptococci on two selective media. Caries Res. 24:36-38.

14. W.G. Wade, M.J. Aldred, and D.M. Walker. 1986. An improve medium for isolation of Strepto-coccus mutans. J. Med. Microbiol. 22:319-323. 